\title{
International journal of advanced manufacturing technology introduction to the special issue
}

\author{
Harold Krikke • Erwin van der Laan
}

Published online: 29 January 2010

(C) Springer-Verlag London Limited 2010

Waste of electrical and electronic equipment (WEEE) is growing. In the USA alone, about 10 million tons of WEEE are generated annually. Europe (7 million tons) and Japan (5 million tons) are not far behind. A large proportion of the waste is exported to developing countries. Although these countries often need the electrical and electronic equipment (EEE) as resources for their own economic growth, its uncontrolled processing (and dumping) poses severe ecological and social problems. Whatever scale is chosen (local or global recovery chains), solutions need to be sustainable with respect to economical, ecological, and social aspects.

The EU was the first to tackle the fast increasing waste stream of EEE in order to prevent growing quantities of equipment from being incinerated or land-filled and to reduce environmental pollution as a result of the uncontrolled release of toxic materials. EU policy is based on the principle of Extended Producer Responsibility (EPR), which is defined by the OECD as "a policy approach in which producers accept significant responsibility, financial, and/or physical, for the treatment or disposal of products." Also, South Korea, Japan, and Taiwan are currently adopting similar policies. In the USA, product stewardship is becoming more accepted and mandatory recycling is in place in some states. Many global companies, such as

H. Krikke $(\bowtie)$

Department of Organisation and Strategy,

Faculty of Economics and Business Administration, CentER,

Tilburg University,

PO Box 90153, 5000 LE Tilburg, Netherlands

e-mail: krikke@uvt.nl

E. van der Laan

Department of Decision and Information Sciences, RSM,

Erasmus University Rotterdam,

Burg. Oudlaan 50, PO Box 1738, 3000 DR Rotterdam,

The Netherlands
DELL, implemented EPR worldwide by offering free recycling services, even when not mandatory in the region at hand.

The effectiveness of EPR and related regulation can be questioned. Market pulls are strong and illegal practices are common. Most legislation is geared towards low quality recycling rather than high quality recovery, while rising prices of raw materials and energy make reuse, remanufacturing and refurbishing an interesting proposition. A global recession can be a strong incentive to strengthen closed loop supply chains as well.

Economically driven remanufacturing is gaining momentum. These are not only returns in their end-of-life state but returned parts and products under warranty, end-oflease or a service level agreement. Rather than recycled these are often repaired or remanufactured. The ongoing move of manufacturing activities to the Far East also creates opportunities for remanufacturing in these areas. Logistics service providers offer new services in "closed loop". Empty container legs are being used for WEEE transport.

This special issue is devoted to publishing the latest significant results of empirical research relating to WEEE flows in a global context. We are very grateful for the positive responses we have received from the authors who submitted papers and the marvelous help provided by a number of referees in the paper reviewing process. After review, seven papers were finally accepted for publication in this special issue.

Zoeteman et al. sketch a global picture of regulated WEEE flows that, under economic pressures, sometimes find a different direction than intended. They particularly address negative impacts of waste receiving countries in Asia and Africa. Alternative, more regional based policy approaches, may provide an alternative. China is already 
working on improved legislation. Yacan Wang et al. give a historical overview of Chinese environmental policy making and the way it has affected the structure of the Chinese recovery system. Veenstra et al. collect survey based data of the current WEEE flows in China and feed them into a Markov model to predict the possible impact of alternative policies. Walther et al. discuss the impact of EPR, i.e. the WEEE directive, from a German (European) standpoint. They also present alternative scenarios for improvement of (cost) performance. Georgiadis and Besiou balance economical and ecological impact of the WEEE-closed-loop supply chain systems in Greece as a function of a set of endogenous and exogenous parameters.

Janse et al. and Geyer and Besiou discuss more specific business-oriented problems, where the value proposition is key. Where Geyer and Blass go into specific details of reuse versus recycling of cellphones, Janse et al. present a tool for reverse logistics quick scans. 